Research Squa
Markel Prognostic Indicator Gastric Cancer for
Lang Yu
The Second Hospital of Anhui Medical University
Runben Jiang
The Second Hospital of Anhui Medical University
Wanjing Chen
The Second Hospital of Anhui Medical University
Yanwei Liu
The Second Hospital of Anhui Medical University
Gui Wang
The Second Hospital of Anhui Medical University
Xin Gong
The Second Hospital of Anhui Medical University
Yong wang ( $\square$ wangyong@ahmu.edu.cn )
The Second Hospital of Anhui Medical University

Preprints are preliminary reports that have not undergone peer review.

They should not be considered conclusive, used to inform clinical practice, or referenced by the media as validated information.

\title{
Novel Prognostic Indicator Combining Inflammatory Indicators and Tumor Markers for Gastric Cancer
}

\author{
Liang Yu \\ University \\ The Second Hospital of Anhui Medical University \\ Wanjing Chen \\ Yanwei Liu \\ The Second Hospital of Anhui Medical University \\ Xin Gong \\ The Second Hospital of Anhui Medical University
}

\section{Research Article}

Keywords: Gastric cancer, Inflammatory indicators, Tumor markers, Neutrophil-to-lymphocyte ratio, Carbohydrate antigen 19-9.

Posted Date: June 28th, 2022

DOI: https://doi.org/10.21203/rs.3.rs-1268760/v2

License: (9) (1) This work is licensed under a Creative Commons Attribution 4.0 International License. Read Full License 


\section{Abstract \\ Background}

Gastric cancer (GC) is one of the most common malignant tumors worldwide, and we hope to identify an economical but practical prognostic indicator. It has been reported that inflammatory indicators and tumor markers are associated with GC progression and are widely used to predict prognosis. However, existing prognostic models do not comprehensively analyze these predictors.

\section{Methods}

This study retrospectively reviewed 893 consecutive patients who underwent curative gastrectomy from January 1, 2012, to December 31, 2015, in the Second Hospital of Anhui Medical University. Prognostic factors predicting overall survival (OS) were analyzed using univariate and multivariate Cox regression analyses. Nomograms including independent prognostic factors were plotted for predicting survival.

\section{Results}

Ultimately, 425 patients were enrolled in this study. Multivariate analyses demonstrated that the neutrophil-to-lymphocyte ratio (NLR, total neutrophil count/lymphocyte count $\left.{ }^{\star} 100 \%\right)$ and CA19-9 were independent prognostic factors for OS $(p=0.001, p=0.016)$. The NLR-CA19-9 score (NCS), constructed as the combination of the NLR and CA19-9, was significantly associated with worse clinicopathological characteristics and OS ( $p<0.05)$. Multivariate analyses revealed that the NCS was an independent prognostic factor for OS (NCS1: $p<0.001, \mathrm{HR}=3.172,95 \% \mathrm{Cl}=2.120-4.745 ; \mathrm{NCS} 2: p<0.001, \mathrm{HR}=3.052,95 \% \mathrm{Cl}=$ 1.928-4.832). Compared with traditional predictive indices, the NCS had the highest AUC for 12-month survival, 36-month survival, 60-month survival and OS $(A U C=0.654,0.730,0.811,0.803$, respectively). The nomogram had a higher Harrell's C-index than TNM stage alone (0.788 vs. 0.743$)$.

\section{Conclusions}

The NCS provides more accurately predicts the prognosis of GC patients, and its predictive value is significantly better than that of traditional inflammatory indicators or tumor markers. It is an effective complement to existing GC assessment systems.

\section{Introduction}

Gastric cancer (GC) is the fifth-most common malignancy in humans and ranks third in tumor-related mortality according to the latest epidemiologic data ${ }^{[1]}$. Radical resection combined with chemotherapy has consistently been the core method for curing GC. Unfortunately, due to the highly aggressive nature of GC, almost $50 \%$ of patients suffer from tumor recurrence or metastasis after curative resection, and the 5 -year survival rate remains less than $30 \%$ [2, 3] . Currently, the most common criteria used to predict GC patients' long-term outcomes include the TNM staging system, tumor markers and inflammation indicators, but clinical outcomes can vary in patients who have the same stages and similar treatment regimens ${ }^{[4,5,6]}$, indicating that these systems provide incomplete prognostic information.

In 1863, Virchow first discovered the relationship between inflammation and cancer ${ }^{[7]}$; subsequently, an increasing number of related studies were carried out. A growing number of studies have proven the relationship between malignant tumors and inflammation ${ }^{[8,9,10,11,12]}$. Many scholars believe that immune status is closely related to survival in patients with various malignancies, including GC $[6,13,14,15]$. The neutrophil-to-lymphocyte ratio (NLR) is an significant prognostic indicator of gastric cancer. Current researchers not only believe that gastric cancer patients with higher NLRs have a poorer prognosis ${ }^{[9,16]}$ but also indicate to a certain extent that the incidence of complications after surgery, such as anastomotic leakage, has increased ${ }^{[16,17]}$. The NLR has been adopted for prognostic evaluation in many cancers, as well as the platelet-to-lymphocyte ratio (PLR) and lymphocyte-to-monocyte ratio (LMR).

The relationship between GC and tumor markers has basically been clarified, and a series of studies have explored the value of tumor markers in the diagnosis and prognosis of gastric cancer ${ }^{[18,19,20]}$. At the same time, tumor markers, such as carcinoembryonic antigen (CEA) and CA19-9, have been used to determine prognosis and monitor the therapeutic effects of treatments. The level of CEA may be increased in gastric carcinoma, lung carcinoma, and especially colorectal carcinoma, while CA19-9 is used mainly as a specific marker for pancreatic cancer.

However, these indicators remain controversial. For both inflammation indicators and tumor markers, the specificity and sensitivity in predicting the long-term outcome of GC patients alone are poor, and thus there is an urgent need for a new, easy method to predict GC more accurately and perform targeted follow-up treatment and observation for patients who may have a poorer prognosis. Therefore, we attempted to combine inflammation indicators and tumor markers with high predictive value to predict the prognosis of GC patients more accurately. In addition, we used prospective clinical data to investigate whether the new indicator could effectively predict postoperative outcomes of GC and compared its predictive value with other traditional indices.

\section{Materials And Methods}

\section{Patients}

Between January 1, 2012, and December 31, 2015, a total of 893 consecutive patients admitted to the Second Hospital of Anhui Medical University were recruited for the trial. Patient eligibility criteria of this study included the following: (1) all patients who underwent gastrectomy with curative R0 resection, (2) 
postoperative pathology confirmed GC, (3) no active inflammatory, chronic infection or autoimmune rheumatic diseases, and (4) no other malignancies. Patients who met the following criteria were excluded from this study: (1) serious complications or death that occurred within 15 days after operative, (2) treatment with neoadjuvant chemotherapy, (3) lack of inflammation and tumor marker data, and (4) acute complications such as perforation or bleeding. All patients, except for those with pTNM stage I, received 6-8 cycles of postoperative chemotherapy based on fluorouracil combined with platinum. This study was reviewed and approved by the Ethical Review Committee of the Second Hospital of Anhui Medical University. The patients were informed orally or in writing about the relevant matters of the study. All patients expressed their complete understanding of the study and signed an informed consent form.

\section{Data collection}

The collection of clinical indicators included basic demographic information (age, sex), routine blood tests (total peripheral neutrophils, lymphocyte count, monocyte count, platelet count, CEA, CA19-9) and tumor-related information (size, depth, differentiation, Borrmann type, lymph node, distant metastasis, pathological stage). All blood test data were collected 1 week before surgery. The NLR was calculated by dividing the neutrophil count by the lymphocyte count. The PLR was calculated by dividing the platelet count by the lymphocyte count. The LMR was calculated by dividing the lymphocyte count by the monocyte count. The clinical stage of GC was determined following the eighth American Joint Committee on Cancer (AJCC) guidelines. The optimal cutoff values of CEA $(5 \mathrm{ng} / \mathrm{ml})$ and CA19-9 $(37 \mathrm{U} / \mathrm{ml})$ were determined by the standards of our hospital.

\section{Follow-up}

After sugery, all patients were followed by radiology and laboratory tests every 3 months for 2 years and every 6 months for 2-5 years. In addition, examinations, including chest radiography, endoscopy, or abdominal and pelvic CT, were performed at least once per year. The follow-up period lasted 5 years after surgery or to the date of death. Overall survival (OS) was defined as the time interval from surgery to the last follow-up or to death from any cause.

\section{Statistical analysis}

Continuous variables are reported as means \pm SDs. Receiver operating characteristic (ROC) curves were generated. The optimal cutoff values of the NLR, PLR and LMR were obtained through the ROC curves by calculating the Youden indices corresponding to different cutoff values of each inflammatory index in the ROC curve, and the corresponding cutoff values of the maximum value of the Youden index were used to divide the patients into two groups. A Cox proportional hazards regression model was used to identify the independent predictors associated with $0 \mathrm{~S}$, and variables with a value of $p<0.05$ in the univariate analysis were subsequently included in multivariate analysis. OS was assessed using the Kaplan-Meier method. Differences between the areas under the curve (AUCs) of each inflammatory and tumor marker were compared to determine the predictive value of each index for OS and the postoperative setting time points.

Models with independent prognostic factors were selected to plot the nomogram. The predictive values for survival were determined by Harrell's C-index. In theory, the higher the $\mathrm{C}$-index is, the more precise the prognosis prediction. The decision curve analysis (DCA) plot can be used to represent the model with the greatest net benefits that had the highest clinical use, and it has been widely used to estimate whether the clinical use of diagnostic tests and prediction models would do more good than harm ${ }^{[21]}$. In the current study, DCA was conducted to evaluate the clinical use of the nomogram by quantifying the net benefits over the AJCC staging system. The calibration curve, the best method to visually compare the accordance between the predicted risk and the actual absolute risk, was used to evaluate the consistency of the model. If the calibration curve of the prediction model was closer to the standard curve, the consistency of the nomogram was better ${ }^{[22]}$.

All statistical analyses were performed using SPSS v.22.0 for Windows (SPSS Inc., Chicago, IL, USA). The nomogram, DCA and calibration curves were plotted with R Studio (version 1.1.463, with packages "rms", "survival", "hmisc" and "rmda"). p values less than 0.05 were considered statistically significant.

\section{Results}

\section{Patient clinicopathological characteristics}

Overall, 425 patients were included in the study (Figure 1). There were 311 (73.18\%) males and 114 (26.82\%) females. According to the eighth edition of the AJCC staging system, a total of 68 patients (16.00\%) had TNM stage I, 162 patients (38.12\%) had TNM stage II, 163 patients (38.35\%) had TNM stage III, and 32 patients (7.53\%) had TNM stage IV. Regarding Borrmann types, 230 patients (54.12\%) had Borrmann type I-II, and 195 patients (45.88\%) had Borrmann type III-IV. In addition, there were 168 patients (39.53\%) with tumor sizes greater than $5 \mathrm{~cm}$ and 184 patients (43.29\%) with poor differentiation. The characteristics are detailed in Table 1.

\section{Survival analysis}

In this study, 24 patients were lost during follow-up, with 12-, 36-, and 60-month OS rates of $87.3 \%, 53.9 \%$, and $43.4 \%$, respectively. The median survival time was 42 months. The optimal cutoff points for preoperative NLR, PLR and LMR for postoperative survivals were obtained by calculating the maximum Youden index of the ROC curves, which were 2.46, 127.8 and 4.93, respectively (Figure 2, Table 2), and based on these values, the entire sample was divided into two groups to identify the independent predictors associated with survival. The results of univariate analysis for the whole sample revealed that age, tumor size, differentiation, Borrmann type, tumor depth, lymph node involvement, distant metastasis, pTNM, CEA, CA19-9, NLR, PLR and LMR were related to OS. Further multivariate analyses revealed that age, tumor depth, pTNM, CA19-9 and NLR were independent risk factors for 0S $(p=0.038,0.009,<0.001,0.016,0.001$, respectively) (Table 3). Kaplan-Meier survival curves comparing the OS of each hematological parameter showed that elevated CEA, CA19-9, NLR, and PLR and decreased LMR were associated with reduced OS (Figure 3a-e). 


\section{Novel prognosis scores factor}

According to the results of multivariate analysis, a novel prognostic prediction system involving the NLR-CA19-9 score (NCS), which combines the CA19-9 level and the NLR, was established. Based on this, the scoring standard of the comprehensive index was obtained, which ranged from 0 to 2 . We defined NLR<2.46 and CA19-9 $\leq 37 \mathrm{U} / \mathrm{ml}$ as an NCS of $0, \mathrm{NLR} \geq 2.46$ or CA19-9 $₫ 37 \mathrm{U} / \mathrm{ml}$ as an NCS 1 , and NLR $\geq 2.46$ and CA19-9 $₫ 37 \mathrm{U} / \mathrm{ml}$ as an NCS of 2 . The NCS was 0 for 168 (39.53\%) patients, 1 for 175 (41.18\%) patients, and 2 for 82 (19.29\%) patients. The association between the NCS and the clinicopathological characteristics of patients with GC is demonstrated in Table 4. A higher NCS was significantly associated with worse clinicopathological characteristics, such as tumor depth, lymph node involvement, pTNM stage, CEA, PLR and LMR. We continued to analyze the statistical relationship of the NCS and other clinicopathological characteristics with survival. The results showed that the NCS was also an independent prognostic factor for postoperative OS in GC patients, in addition to age, tumor depth, and pTNM ( $p<0.001,0.024,0.018$, and $<0.001$, respectively) (Table 5). Similarly, we performed Kaplan-Meier survival curves based on the NCS, and the results showed that the higher the NCS was, the shorter the survival period, which indicated a worse prognosis (Figure 4).

\section{Predictive value}

To compare the predictive power of the NCS with other hematological parameters for OS and 12-, 36-, and 60-month survival, we compared the AUC of each inflammatory and tumor marker with that of the NCS. It was confirmed that the NCS had the highest AUC $(0.803,0.763,0.811$, respectively) for OS and 36 - and 60 -month survival, respectively and the differences were all statistically significant $(p<0.05)$ (Figure 5a-d, Table 6). The higher AUC further confirmed the favorable sensitivity and specificity of the NCS.

\section{Nomogram}

To make individualized predictions of the survival probability in all GC patients, we combined all independent prognostic factors, including age, TNM stage, tumor depth and NCS, as described in detail in Table 4, and established a nomogram for the entire cohort (Figure 6).

Discrimination and calibration are both important features of model performance. In this study, Harrell's C-index of our nomogram (0.788, 95\% Cl: 0.813-0.762) was higher than that of TNM stage alone $(0.743,95 \% \mathrm{Cl}$ : $0.770-0.717)$, indicating a more accurate and robust performance estimate. In addition, DCA of the novel nomogram revealed a superior net clinical benefit over the 8th AJCC TNM staging system alone and exhibited higher clinical use than the AJCC staging system in OS prediction (Figure 7). Furthermore, the calibration plots showed super agreement between the actual and predicted survival (Figure 8a-c). All the above results show the better predictive capability of the established nomogram over the existing AJCC staging system.

\section{Discussion}

Advances in modern medicine have allowed scholars to gradually turned their attention to the early treatment and follow-up of various malignant tumors, which puts forward extremely high requirements on how to distinguish patients with a poor prognosis. To date, researchers have established several scoring systems that reflect inflammation or tumor status ${ }^{[23,24,25]}$. Our study enrolled 425 GC patients and found that the NLR and CA19-9 were independent prognostic factors for postoperative OS. Based on this, we developed a novel index combining these inflammatory and tumor markers and confirmed that the new index could provide better prognostic value than either the NLR or CA19-9 alone.

Inflammation is an important characteristic of the tumor microenvironment and is associated with the promotion, progression and metastasis of tumors ${ }^{[8]}$. Tumor cells produce cancer-related inflammatory mediators, resulting in relative neutrophilia, thrombocytosis, and lymphocytopenia. These phenomena cause an elevated NLR and PLR ${ }^{[26]}$ and further affect the occurrence, progression and metastasis of tumors ${ }^{[27]}$. Neutrophils are currently believed to promote cancer cell proliferation and metastasis by producing proangiogenic chemokines and vascular endothelial growth factor ${ }^{[28,29,30]}$, and lymphocytes are antitumor factors involved in cytotoxic activity ${ }^{[31]}$. Numerous studies have proven the relationship between a high NLR and poor outcomes in various malignancies, such as gastric cancer ${ }^{[9,16]}$, colon cancer ${ }^{[13]}$ and pancreatic cancer ${ }^{[32]}$. The present study revealed the NLR as an independent factor with a cutoff value of 2.46 , and its AUC was higher than that of other hematological parameters.

Carbohydrate antigen (CA) 19 - 9 is one of the most common tumor markers of gastric cancer, and positivity is frequently related to tumor stage, poor prognosis, recurrence and metastasis ${ }^{[18,19,20]}$. Jing et al. ${ }^{[19]}$ found that surgery can significantly reduce the level of CA19-9; if the level returns to normal after surgery, the prognosis is not significantly different from that of patients with normal CA19-9 before surgery. As confirmed in our study, the prognosis of GC patients with low levels of CA19-9 before surgery was significantly better than that of patients with high levels. Of course, we consider the NLR and CA19-9 to represent not only simple changes in several indicators but also the balance of tumor and antitumor status in the body. When this balance is broken, tumor promotion is prioritized, leading to a poor prognosis.

Unfortunately, previous conclusions on these indicators have not always been consistent. Some scholars have insisted that there was no significant correlation between the preoperative NLR and survival time in GC patients ${ }^{[33,34,35]}$. In addition, controversy about CA19-9 also exists. Researchers have reported a low positive rate of CA19-9 in GC patients ${ }^{[36,37]}$. In addition, some scholars believe that CA19-9 cannot accurately predict the prognosis of patients with $\mathrm{GC}^{[18]}$, especially early $\mathrm{GC}^{[37]}$. This means that using an indicator alone to predict prognosis may lose some potential information, resulting in limited predictive value. In this study, we discussed the predictive significance of various inflammatory indicators and tumor markers in the prognosis of GC in detail and innovatively introduced a new index, the NLR-CA19-9 score (NCS). We found that the NCS not only could serve as an independent prognostic factor but also had a higher AUC than other inflammatory and tumor markers for OS, 12-, 36-, and 60-month survival, which means that the NCS has a stable prognostic ability that was better than that of other indicators. It was worth noting that there were no significant differences in AUC between the NCS and NLR, PLR, or CEA at 12-month after surgery. We believed that the survival of patients at 12 months after surgery was relatively higher ( $87.3 \%)$, resulting in no statistically significant difference. With the progress of follow-up, the survival of patients had declined, the differences had gradually become apparent. Therefore, the

Page $4 / 19$ 
differences were all statistically significant for OS and 36 - and 60-month survival $(p<0.05)$. Moreover, a model including the NCS (C-index: 0.788$)$ was superior to that constructed without it (C-index: 0.743 ) in predicting OS after radical gastrectomy. Importantly, the novel index in our model could be conveniently attained from routine laboratory inspection, which was advantageous because it avoids the potential unavailability of other predictors.

The results of this study that the NCS, as a novel scoring system, has favorable sensitivity and specificity in predicting the long-term postoperative outcomes of GC patients and could provide more precise and informative prognostic value than other indicators. This new indicator may have vital use in predicting recurrence, therapeutic intervention, and surveillance strategies, especially when incorporating TNM stage. For example, patients with a higher NCS could be strongly recommended to receive postoperative multimodal treatment, such as chemotherapy, immunotherapy or targeted therapy. More regular follow-up schedules could simultaneously be offered to detect recurrence, which may provide a survival benefit for GC patients.

Several limitations remain in our present study. First, the main drawback of our study is its retrospective nature, and bias in the process of patient selection cannot be avoided. Second, because the specific time of tumor recurrence in some patients cannot be completely determined, we did not study the relationship between various indicators and postoperative progression-free survival (PFS). Third, since our sample was not particularly sufficient in size, deviations in the results may be present, but we will continue to expand the sample size to verify our results in the future.

\section{Conclusion}

In conclusion, to the best of our knowledge, the NCS is an independent prognostic factor for OS in GC patients and provides great value in predicting postoperative overall survival. It is an effective complement to existing GC assessment systems. Future studies should consider combining the NCS into the current TNM system to more specifically predict the prognosis of GC patients, who will be likely to benefit from a rigorous follow-up strategy.

\section{Declarations}

Ethics approval and consent to participate: This study was reviewed and approved by the Ethical Review Committee of the Second Hospital of Anhui Medical University. All patients expressed their complete understanding of the study and signed an informed consent form. We confirmed that all methods were performed in accordance with the relevant guidelines and regulations.

Consent for publication: Not applicable.

Availability of data and materials: The datasets generated and/or analysed during the current study are not publicly available due to personal request but are available from the corresponding author on reasonable request.

Competing interests: The authors declared no competing interests.

Funding: This study was supported by the 2019 Provincial Key Laboratory of Medical Physics and Technology Safety and Security Open Fund (No. LMPT201908 to Y Wang). The role of microbial-gut-brain axis in laparoscopic sleeve gastrectomy on cognitive function of fat patients and related mechanisms (No. 2020LCZD07 to Y Wang). Study of environmental pathogenic factors and mechanisms of metabolic diseases Research (No. 2021 lcxk033 to $Y$ Wang).

Authors' Contributions: 1. Liang Yu - Helped conceive the idea, acquisition of data, analysis, drafting of work, final approval, and agreement to be accountable for all aspects of the work.

2. Runben Jiang - Helped with acquisition of data, drafted the manuscript, final approval, and agreement to be accountable for all aspects of the work.

3. Wanjing Chen - Helped with acquisition of data, drafted the manuscript, final approval, and agreement to be accountable for all aspects of the work.

4. Yanwei Liu - Helped with acquisition of data, drafted the manuscript, final approval, and agreement to be accountable for all aspects of the work.

5. Gui Wang - Helped with interpretation of data, revised the manuscript, final approval, and agreement to be accountable for all aspects of the work.

6. Xin Gong - Helped with interpretation of data, revised the manuscript, final approval, and agreement to be accountable for all aspects of the work.

7. Yong Wang - Helped with conception and data analysis, drafted the manuscript, final approval, and agreement to be accountable for all aspects of the work.

Acknowledgements: The authors are grateful for the kind assistance from their colleagues.

\section{References}

1. Bray F, Ferlay J, Soerjomataram I, Siegel RL, Torre LA, Jemal A. Global cancer statistics 2018: GLOBOCAN estimates of incidence and mortality worldwide for 36 cancers in 185 countries. CA Cancer J Clin. 2018;68(6):394-424.

2. Duarte HO, Gomes J, Machado JC, Reis CA. Gastric cancer: Basic aspects. Helicobacter. 2018;23 Suppl 1:e12523.

3. Li S, Cong X, Gao H, Lan X, Li Z, Wang W, Song S, Wang Y, Li C, Zhang H, Xue Y, Zhao Y. Tumor-associated neutrophils induce EMT by IL-17a to promote migration and invasion in gastric cancer cells. J Exp Clin Cancer Res. 2019;38(1):6.

4. Sasako M, Inoue M, Lin JT, Khor C, Yang HK, Ohtsu A. Gastric Cancer Working Group report. Jpn J Clin Oncol. 2010;40 Suppl 1:i28-i37. 
5. Noh SH, Park SR, Yang HK, Chung HC, Chung IJ, Kim SW, Kim HH, Choi JH, Kim HK, Yu W, Lee JI, Shin DB, Ji J, Chen JS, Lim Y, Ha S, Bang YJ. Adjuvant capecitabine plus oxaliplatin for gastric cancer after D2 gastrectomy (CLASSIC): 5-year follow-up of an open-label, randomised phase 3 trial. Lancet Oncol. 2014;15(12):1389-1396.

6. Wang H, Ding Y, Li N, Wu L, Gao Y, Xiao C, Jiang H, Zheng Y, Mao C, Deng J, Wang H, Xu N. Prognostic Value of Neutrophil-Lymphocyte Ratio, PlateletLymphocyte Ratio, and Combined Neutrophil-Lymphocyte Ratio and Platelet-Lymphocyte Ratio in Stage IV Advanced Gastric Cancer. Front Oncol. 2020;10:841.

7. Balkwill F, Mantovani A. Inflammation and cancer: back to Virchow?. Lancet. 2001;357(9255):539-545.

8. Mantovani A, Allavena P, Sica A, Balkwill F. Cancer-related inflammation. Nature. 2008;454(7203):436-444.

9. Fang T, Wang Y, Yin X, Zhai Z, Zhang Y, Yang Y, You Q, Li Z, Ma Y, Li C, Song H, Shi H, Zhang Y, Yu X, Gao H, Sun Y, Xie R, Xue Y. Diagnostic Sensitivity of NLR and PLR in Early Diagnosis of Gastric Cancer. J Immunol Res. 2020;2020:9146042.

10. Hirano T. IL-6 in inflammation, autoimmunity and cancer. Int Immunol. 2021;33(3):127-148.

11. Hou J, Karin M, Sun B. Targeting cancer-promoting inflammation - have anti-inflammatory therapies come of age?. Nat Rev Clin Oncol. 2021;18(5):261279.

12. Inoue H, Kosuga T, Kubota T, Konishi H, Shiozaki A, Okamoto K, Fujiwara H, Otsuji E. Significance of a preoperative systemic immune-inflammation index as a predictor of postoperative survival outcomes in gastric cancer. World J Surg Oncol. 2021;19(1):173.

13. Dolan RD, McSorley ST, Park JH, Watt DG, Roxburgh CS, Horgan PG, McMillan DC. The prognostic value of systemic inflammation in patients undergoing surgery for colon cancer: comparison of composite ratios and cumulative scores. Br J Cancer. 2018;119(1):40-51.

14. Nozoe T, Iguchi T, Egashira A, Adachi E, Matsukuma A, Ezaki T. Significance of modified Glasgow prognostic score as a useful indicator for prognosis of patients with gastric carcinoma. Am J Surg. 2011;201(2):186-191.

15. Lu J, Xu BB, Zheng ZF, Xie JW, Wang JB, Lin JX, Chen QY, Cao LL, Lin M, Tu RH, Huang ZN, Zheng CH, Huang CM, Li P. CRP/prealbumin, a novel inflammatory index for predicting recurrence after radical resection in gastric cancer patients: post hoc analysis of a randomized phase III trial. Gastric Cancer. 2019;22(3):536-545.

16. Huang Z, Liu Y, Yang C, Li X, Pan C, Rao J, Li N, Liao W, Lin L. Combined neutrophil / platelet / lymphocyte / differentiation score predicts chemosensitivity in advanced gastric cancer. BMC Cancer. 2018;18(1):515.

17. Radulescu D, Baleanu VD, Padureanu V, Radulescu PM, Bordu S, Patrascu S, Socea B, Bacalbasa N, Surlin MV, Georgescu I, Georgescu EF. Neutrophil/Lymphocyte Ratio as Predictor of Anastomotic Leak after Gastric Cancer Surgery. Diagnostics (Basel). 2020;10(10):799.

18. Gong X, Zhang H. Diagnostic and prognostic values of anti-helicobacter pylori antibody combined with serum CA724, CA19-9, and CEA for young patients with early gastric cancer. J Clin Lab Anal. 2020;34(7):e23268.

19. Jing R, Cui M, Ju S, Pan S. The Changes and Clinical Significance of Preoperative and Postoperative Serum CEA and CA19-9 in Gastric Cancer. Clin Lab. 2020;66(4).

20. Kambara Y, Miyake H, Nagai H, Yoshioka Y, Shibata K, Asai S, Yuasa N. CA19-9 is a significant prognostic marker of patients with stage III gastric cancer. Eur J Surg Oncol. 2020;46(10 Pt A):1918-1924.

21. Vickers AJ, Van Calster B, Steyerberg EW. Net benefit approaches to the evaluation of prediction models, molecular markers, and diagnostic tests. BMJ. 2016;352:i6.

22. Guo L, Wang Q, Chen K, Liu HP, Chen X. Prognostic Value of Combination of Inflammatory and Tumor Markers in Resectable Gastric Cancer. J Gastrointest Surg. 2021;25(10):2470-2483.

23. Luo G, Jin K, Deng S, Cheng H, Fan Z, Gong Y, Qian Y, Huang Q, Ni Q, Liu C, Yu X. Roles of CA19-9 in pancreatic cancer: Biomarker, predictor and promoter. Biochim Biophys Acta Rev Cancer. 2021;1875(2):188409.

24. Ng K, Stenzl A, Sharma A, Vasdev N. Urinary biomarkers in bladder cancer: A review of the current landscape and future directions. Urol Oncol. 2021;39(1):41-51.

25. Horii M, Matsushita T. Regulatory B cells and T cell Regulation in Cancer. J Mol Biol. 2021;433(1):166685.

26. Arigami T, Okumura H, Matsumoto M, Uchikado Y, Uenosono Y, Kita Y, Owaki T, Mori S, Kurahara H, Kijima Y, Ishigami S, Natsugoe S. Analysis of the Fibrinogen and Neutrophil-Lymphocyte Ratio in Esophageal Squamous Cell Carcinoma: A Promising Blood Marker of Tumor Progression and Prognosis. Medicine (Baltimore). 2015;94(42):e1702.

27. Fankhauser CD, Sander S, Roth L, Gross O, Eberli D, Sulser T, Seifert B, Beyer J, Hermanns T. Systemic inflammatory markers have independent prognostic value in patients with metastatic testicular germ cell tumours undergoing first-line chemotherapy. Br J Cancer. 2018;118(6):825-30

28. Liang W, Ferrara N. The Complex Role of Neutrophils in Tumor Angiogenesis and Metastasis. Cancer Immunol Res. 2016;4(2):83-91.

29. Swierczak A, Mouchemore KA, Hamilton JA, Anderson RL. Neutrophils: important contributors to tumor progression and metastasis. Cancer Metastasis Rev. 2015;34(4):735-751.

30. McCourt M, Wang JH, Sookhai S, Redmond HP. Proinflammatory mediators stimulate neutrophil-directed angiogenesis. Arch Surg. 1999;134(12):13251332.

31. Li Z, Li S, Ying X, Zhang L, Shan F, Jia Y, Ji J. The clinical value and usage of inflammatory and nutritional markers in survival prediction for gastric cancer patients with neoadjuvant chemotherapy and D2 lymphadenectomy. Gastric Cancer. 2020;23(3):540-549.

32. Bhatti I, Peacock O, Lloyd G, Larvin M, Hall RI. Preoperative hematologic markers as independent predictors of prognosis in resected pancreatic ductal adenocarcinoma: neutrophil-lymphocyte versus platelet-lymphocyte ratio. Am J Surg. 2010;200(2):197-203. 
33. Zhu GS, Tian SB, Wang H, Ma MG, Liu Y, DU HS, Long YP. Preoperative Neutrophil Lymphocyte Ratio and Platelet Lymphocyte Ratio Cannot Predict Lymph Node Metastasis and Prognosis in Patients with Early Gastric Cancer: a Single Institution Investigation in China. Curr Med Sci. 2018;38(1):78-84.

34. Toyokawa T, Muguruma K, Tamura T, Sakurai K, Amano R, Kubo N, Tanaka H, Yashiro M, Hirakawa K, Ohira M. Comparison of the prognostic impact and combination of preoperative inflammation-based and/or nutritional markers in patients with stage II gastric cancer. Oncotarget. 2018;9(50):2935129364.

35. Sun KY, Xu JB, Chen SL, Yuan YJ, Wu H, Peng JJ, Chen CQ, Guo P, Hao YT, He YL. Novel immunological and nutritional-based prognostic index for gastric cancer. World J Gastroenterol. 2015;21(19):5961-5971.

36. Liang Y, Wang W, Fang C, Raj SS, Hu WM, Li QW, Zhou ZW. Clinical significance and diagnostic value of serum CEA, CA19-9 and CA72-4 in patients with gastric cancer. Oncotarget. 2016;7(31):49565-49573.

37. Yu J, Zheng W. An Alternative Method for Screening Gastric Cancer Based on Serum Levels of CEA, CA19-9, and CA72-4. J Gastrointest Cancer. 2018;49(1):57-62.

\section{Tables}

Table 1. Patients clinicopathological characteristics 


\begin{tabular}{|c|c|}
\hline Variables & $\mathrm{n}(\%)$ or mean $\pm \mathrm{SD}$ \\
\hline \multicolumn{2}{|l|}{ Sex } \\
\hline Female & $114(26.82 \%)$ \\
\hline Male & 311 (73.18\%) \\
\hline \multicolumn{2}{|l|}{ Age } \\
\hline$<65$ years & $216(50.82 \%)$ \\
\hline$\geq 65$ years & $209(49.18 \%)$ \\
\hline \multicolumn{2}{|l|}{ Tumor size } \\
\hline$<5 \mathrm{~cm}$ & 257 (60.47\%) \\
\hline$\geq 5 \mathrm{~cm}$ & $168(39.53 \%)$ \\
\hline \multicolumn{2}{|l|}{ Differentiation } \\
\hline Moderate/Well & $241(56.71 \%)$ \\
\hline Poor & $184(43.29 \%)$ \\
\hline \multicolumn{2}{|l|}{ Borrmann type } \\
\hline I-II & $230(54.12 \%)$ \\
\hline III-IV & 195 (45.88\%) \\
\hline \multicolumn{2}{|l|}{ Tumor depth } \\
\hline $\mathrm{T} 1$ & 45 (10.59\%) \\
\hline $\mathrm{T} 2$ & $47(11.06 \%)$ \\
\hline T3 & $230(54.12 \%)$ \\
\hline T4 & 103 (24.24\%) \\
\hline \multicolumn{2}{|l|}{ Lymph node } \\
\hline NO & $100(23.53 \%)$ \\
\hline N1 & $181(42.59 \%)$ \\
\hline N2 & $103(24.24 \%)$ \\
\hline N3 & $41(9.65 \%)$ \\
\hline \multicolumn{2}{|c|}{ Distant metastasis } \\
\hline MO & 393 (92.47\%) \\
\hline M1 & $32(7.53 \%)$ \\
\hline \multicolumn{2}{|l|}{ pTNM stage } \\
\hline 1 & $68(16.00 \%)$ \\
\hline ॥ & $162(38.12 \%)$ \\
\hline III & $163(38.35 \%)$ \\
\hline IV & $32(7.53 \%)$ \\
\hline \multicolumn{2}{|l|}{ CEA } \\
\hline$\leq 5 \mathrm{ng} / \mathrm{ml}$ & $276(64.94 \%)$ \\
\hline$>5 \mathrm{ng} / \mathrm{ml}$ & $149(35.06 \%)$ \\
\hline \multicolumn{2}{|l|}{ CA19-9 } \\
\hline$\leq 37 \mathrm{U} / \mathrm{ml}$ & 317 (74.59\%) \\
\hline$>37 \mathrm{U} / \mathrm{ml}$ & $108(25.41 \%)$ \\
\hline NLR & $4.14 \pm 4.05$ \\
\hline PLR & $161.2 \pm 92.8$ \\
\hline LMR & $4.88 \pm 2.79$ \\
\hline
\end{tabular}

Page 8/19 
Note: NLR: the neutrophil-to-lymphocyte ratio; PLR: the platelet-to-lymphocyte ratio; LMR: the lymphocyte-to-monocyte ratio.

Table 2. The optimal cut-off points of NLR, PLR and LMR

\begin{tabular}{|lllll|}
\hline & Cutoff value & AUC $(95 \% \mathrm{Cl})$ & maximal Youden index & $p$ \\
\hline NLR & 2.46 & $0.778(0.734-0.823)$ & 0.508 & $<0.001$ \\
\hline PLR & 127.8 & $0.635(0.582-0.688)$ & 0.234 & $<0.001$ \\
\hline LMR & 4.93 & $0.287(0.238-0.336)$ & 0.361 & $<0.001$ \\
\hline
\end{tabular}

Note: NLR: the neutrophil-to-lymphocyte ratio; PLR: the platelet-to-lymphocyte ratio; LMR: the lymphocyte-to-monocyte ratio.

Table 3. Univariate and multivariate analyses of variables associated with OS 


\begin{tabular}{|c|c|c|c|c|}
\hline \multirow[t]{2}{*}{ Variables } & \multicolumn{2}{|l|}{ Univariate analysis } & \multicolumn{2}{|l|}{ Multivariate analysis } \\
\hline & Hazard ratio $(95 \% \mathrm{Cl})$ & $p$ & Hazard ratio $(95 \% \mathrm{Cl})$ & $p$ \\
\hline Sex & & 0.728 & & \\
\hline Female & 1 & & & \\
\hline Male & $1.052(0.790-1.403)$ & & & \\
\hline Age & & $<0.001$ & & 0.038 \\
\hline$<65$ years & 1 & & 1 & \\
\hline$\geq 65$ years & $1.963(1.516-2.541)$ & & $1.342(1.017-1.771)$ & \\
\hline Tumor size & & $<0.001$ & & \\
\hline$<5 \mathrm{~cm}$ & 1 & & & \\
\hline$\geq 5 \mathrm{~cm}$ & $1.666(1.294-2.147)$ & & & \\
\hline Differentiation & & 0.008 & & \\
\hline Moderate/Well & 1 & & & \\
\hline Poor & $1.409(1.094-1.814)$ & & & \\
\hline Borrmann type & & $<0.001$ & & \\
\hline III & 1 & & & \\
\hline III-IV & $1.614(1.253-2.079)$ & & & \\
\hline Tumor depth & & $<0.001$ & & 0.009 \\
\hline $\mathrm{T} 1$ & 1 & & 1 & \\
\hline T2 & $4.305(1.215-15.258)$ & 0.024 & $1.218(0.202-7.341)$ & 0.829 \\
\hline T3 & $11.662(3.710-36.658)$ & $<0.001$ & $1.200(0.176-8.203)$ & 0.852 \\
\hline T4 & $41.409(13.073-131.166)$ & $<0.001$ & $2.228(0.317-15.649)$ & 0.421 \\
\hline Lymph node & & $<0.001$ & & \\
\hline NO & 1 & & & \\
\hline N1 & 5.937(3.398-10.375) & $<0.001$ & & \\
\hline N2 & 10.133(5.736-17.902) & $<0.001$ & & \\
\hline N3 & $15.816(8.540-29.291)$ & $<0.001$ & & \\
\hline Distant metastasis & & $<0.001$ & & \\
\hline MO & 1 & & & \\
\hline M1 & $4.458(3.022-6.577)$ & & & \\
\hline pTNM stage & & $<0.001$ & & $<0.001$ \\
\hline 1 & 1 & & & \\
\hline II & $6.519(2.623-16.200)$ & $<0.001$ & 2.673(0.501-14.263) & 0.250 \\
\hline III & $25.415(10.389-62.172)$ & $<0.001$ & $5.570(0.915-33.897)$ & 0.062 \\
\hline IV & $51.590(19.885-133.844)$ & $<0.001$ & $11.700(1.921-71.263)$ & 0.008 \\
\hline CEA & & $<0.001$ & & \\
\hline$\leq 5 \mathrm{ng} / \mathrm{ml}$ & 1 & & & \\
\hline$>5 \mathrm{ng} / \mathrm{ml}$ & $2.098(1.626-2.706)$ & & & \\
\hline CA19-9 & & $<0.001$ & & 0.016 \\
\hline$\leq 37 \mathrm{U} / \mathrm{ml}$ & 1 & & 1 & \\
\hline$>37 \mathrm{U} / \mathrm{ml}$ & $2.937(2.256-3.823)$ & & $1.442(1.072-1.939)$ & \\
\hline NLR & & $<0.001$ & & 0.001 \\
\hline$\leq 2.46$ & 1 & & 1 & \\
\hline$>2.46$ & $4.468(3.303-6.045)$ & & $1.772(1.245-2.522)$ & \\
\hline
\end{tabular}

Page 10/19 


\begin{tabular}{|c|c|}
\hline PLR & $<0.001$ \\
\hline$\leq 127.8$ & 1 \\
\hline$>127.8$ & $1.979(1.518-2.580)$ \\
\hline LMR & $<0.001$ \\
\hline$\leq 4.93$ & 1 \\
\hline$>4.93$ & $0.365(0.276-0.484)$ \\
\hline
\end{tabular}

Note: (1) NLR: the neutrophil-to-lymphocyte ratio; PLR: the platelet-to-lymphocyte ratio; LMR: the lymphocyte-to-monocyte ratio. (2) OS: overall survival.

Table 4. Statistical relationship between the NCS and other variables 


\begin{tabular}{|c|c|c|c|c|}
\hline \multirow[t]{2}{*}{ Variables } & \multicolumn{3}{|l|}{ NCS } & \multirow[t]{2}{*}{$p$} \\
\hline & $0 \mathrm{n}(\%)$ & $1 \mathrm{n}(\%)$ & $2 \mathrm{n}(\%)$ & \\
\hline Sex & & & & 0.585 \\
\hline Female & $44(26.19 \%)$ & $51(29.14 \%)$ & 19(23.17\%) & \\
\hline Male & 124(73.81\%) & $124(70.86 \%)$ & $63(76.83 \%)$ & \\
\hline Age & & & & $<0.001$ \\
\hline$<65$ years & $106(63.10 \%)$ & $85(48.57 \%)$ & $25(30.49 \%)$ & \\
\hline$\geq 65$ years & $62(36.90 \%)$ & $90(51.43 \%)$ & $57(69.51 \%)$ & \\
\hline Tumor size & & & & 0.001 \\
\hline$<5 \mathrm{~cm}$ & $120(71.43 \%)$ & $97(55.43 \%)$ & $40(48.78 \%)$ & \\
\hline$\geq 5 \mathrm{~cm}$ & $48(28.57 \%)$ & $78(44.57 \%)$ & $42(51.22 \%)$ & \\
\hline Differentiation & & & & 0.252 \\
\hline Moderate/Well & $100(9.52 \%)$ & $101(57.71 \%)$ & $40(48.78 \%)$ & \\
\hline Poor & $68(40.48 \%)$ & $74(42.29 \%)$ & $42(51.22 \%)$ & \\
\hline Borrmann type & & & & 0.001 \\
\hline 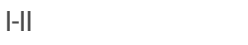 & $109(64.88 \%)$ & $87(49.71 \%)$ & $34(41.46 \%)$ & \\
\hline III-IV & $59(35.12 \%)$ & $88(50.29 \%)$ & $48(58.54 \%)$ & \\
\hline Tumor depth & & & & $<0.001$ \\
\hline T1 & $35(20.83 \%)$ & $10(5.71 \%)$ & $0(0)$ & \\
\hline T2 & $30(17.86 \%)$ & $15(8.57 \%)$ & $2(2.44 \%)$ & \\
\hline T3 & $90(53.57 \%)$ & $100(57.14 \%)$ & $40(48.78 \%)$ & \\
\hline T4 & $13(7.74 \%)$ & $50(28.57 \%)$ & $40(48.78 \%)$ & \\
\hline Lymph node & & & & $<0.001$ \\
\hline NO & $70(41.67 \%)$ & $24(13.71 \%)$ & $6(7.32 \%)$ & \\
\hline $\mathrm{N} 1$ & $63(37.50 \%)$ & $81(46.29 \%)$ & $37(45.12 \%)$ & \\
\hline N2 & $30(17.86 \%)$ & $48(27.43 \%)$ & $25(30.49 \%)$ & \\
\hline N3 & $5(2.98 \%)$ & $22(12.57 \%)$ & $14(17.07 \%)$ & \\
\hline Distant metastasis & & & & $<0.001$ \\
\hline MO & 166(98.81\%) & 157(89.71\%) & $70(85.37 \%)$ & \\
\hline M1 & $2(1.19 \%)$ & $18(10.29 \%)$ & $12(14.63 \%)$ & \\
\hline pTNM stage & & & & $<0.001$ \\
\hline I & $53(31.55 \%)$ & $14(8.00 \%)$ & $1(1.22 \%)$ & \\
\hline ॥ & $75(44.64 \%)$ & $69(39.43 \%)$ & $18(21.95 \%)$ & \\
\hline III & $38(22.62 \%)$ & $74(42.29 v)$ & $51(62.20 \%)$ & \\
\hline IV & $2(1.19 \%)$ & $18(10.29 \%)$ & $12(14.63 \%)$ & \\
\hline CEA & & & & $<0.001$ \\
\hline$\leq 5 \mathrm{ng} / \mathrm{ml}$ & $130(77.38 \%)$ & $117(66.86 \%)$ & $29(35.37 \%)$ & \\
\hline$>5 \mathrm{ng} / \mathrm{ml}$ & $38(22.62 \%)$ & $58(33.14 \%)$ & $53(64.63 \%)$ & \\
\hline PLR & & & & $<0.001$ \\
\hline$\leq 127.8$ & $112(66.67 \%)$ & $62(35.43 \%)$ & $20(24.39 \%)$ & \\
\hline$>127.8$ & $56(33.33 \%)$ & $113(64.57 \%)$ & $62(75.61 \%)$ & \\
\hline LMR & & & & $<0.001$ \\
\hline$\leq 4.93$ & $52(30.95 \%)$ & $114(65.14 \%)$ & $71(86.59 \%)$ & \\
\hline$>4.93$ & $116(69.05 \%)$ & $61(34.86 \%)$ & $11(13.41 \%)$ & \\
\hline
\end{tabular}

Page 12/19 
Note: (1) PLR: the platelet-to-lymphocyte ratio; LMR: the lymphocyte-to-monocyte ratio. (2) NCS: the NLR-CA19-9 score.

Table 5. Univariate and multivariate analyses incorporating the NCS 


\begin{tabular}{|c|c|c|c|c|}
\hline \multirow[t]{2}{*}{ Variables } & \multicolumn{2}{|l|}{ Univariate analysis } & \multicolumn{2}{|l|}{ Multivariate analysis } \\
\hline & Hazard ratio $(95 \% \mathrm{Cl})$ & $p$ & Hazard ratio $(95 \% \mathrm{Cl})$ & $p$ \\
\hline Sex & & 0.728 & & \\
\hline Female & 1 & & & \\
\hline Male & 1.052(0.790-1.403) & & & \\
\hline Age & & $<0.001$ & & 0.024 \\
\hline$<65$ years & 1 & & 1 & \\
\hline$\geq 65$ years & $1.963(1.516-2.541)$ & & $1.375(1.042-1.813)$ & \\
\hline Tumor size & & $<0.001$ & & \\
\hline$<5 \mathrm{~cm}$ & 1 & & & \\
\hline$\geq 5 \mathrm{~cm}$ & $1.666(1.294-2.147)$ & & & \\
\hline Differentiation & & 0.008 & & \\
\hline Moderate/Well & 1 & & & \\
\hline Poor & $1.409(1.094-1.814)$ & & & \\
\hline Borrmann type & & $<0.001$ & & \\
\hline I-II & 1 & & & \\
\hline III-IV & $1.614(1.253-2.079)$ & & & \\
\hline Tumor depth & & $<0.001$ & & 0.018 \\
\hline T1 & 1 & & 1 & \\
\hline T2 & $4.305(1.215-15.258)$ & 0.024 & $1.332(0.221-8.038)$ & 0.755 \\
\hline T3 & 11.662(3.710-36.658) & $<0.001$ & $1.240(0.181-8.488)$ & 0.827 \\
\hline $\mathrm{T} 4$ & $41.409(13.073-131.166)$ & $<0.001$ & $2.202(0.313-15.492)$ & 0.428 \\
\hline Lymph node & & $<0.001$ & & \\
\hline NO & 1 & & & \\
\hline $\mathrm{N} 1$ & 5.937(3.398-10.375) & $<0.001$ & & \\
\hline $\mathrm{N} 2$ & $10.133(5.736-17.902)$ & $<0.001$ & & \\
\hline N3 & $15.816(8.540-29.291)$ & $<0.001$ & & \\
\hline Distant metastasis & & $<0.001$ & & \\
\hline MO & 1 & & & \\
\hline M1 & $4.458(3.022-6.577)$ & & & \\
\hline pTNM stage & & $<0.001$ & & $<0.001$ \\
\hline I & 1 & & 1 & \\
\hline II & $6.519(2.623-16.200)$ & $<0.001$ & $2.396(0.446-12.859)$ & 0.308 \\
\hline III & $25.415(10.389-62.172)$ & $<0.001$ & $5.445(0.889-33.357)$ & 0.067 \\
\hline IV & $51.590(19.885-133.844)$ & $<0.001$ & $10.274(1.677-62.953)$ & 0.012 \\
\hline CEA & & $<0.001$ & & \\
\hline$\leq 5 \mathrm{ng} / \mathrm{ml}$ & 1 & & & \\
\hline$>5 \mathrm{ng} / \mathrm{ml}$ & $2.098(1.626-2.706)$ & & & \\
\hline PLR & & $<0.001$ & & \\
\hline$\leq 127.8$ & 1 & & & \\
\hline$>127.8$ & $1.979(1.518-2.580)$ & & & \\
\hline LMR & & $<0.001$ & & \\
\hline$\leq 4.93$ & 1 & & & \\
\hline$>4.93$ & $0.365(0.276-0.484)$ & & & \\
\hline
\end{tabular}

Page 14/19 


\begin{tabular}{|c|c|c|c|c|}
\hline NCS & & $<0.001$ & & $<0.001$ \\
\hline 0 & 1 & & 1 & \\
\hline 1 & $5.874(4.048-8.524)$ & $<0.001$ & $3.172(2.120-4.745)$ & $<0.001$ \\
\hline 2 & $8.710(5.795-13.093)$ & $<0.001$ & $3.052(1.928-4.832)$ & $<0.001$ \\
\hline
\end{tabular}

Note: (1) PLR: the platelet-to-lymphocyte ratio; LMR: the lymphocyte-to-monocyte ratio. (2) NCS: the NLR-CA19-9 score.

Table 6. Comparison of the AUC between inflammatory indicators and tumor markers

\begin{tabular}{|c|c|c|c|c|c|c|c|c|c|c|c|c|}
\hline \multirow[t]{2}{*}{ variables } & \multicolumn{3}{|l|}{ OS } & \multicolumn{3}{|l|}{$12 \mathrm{mo}$} & \multicolumn{3}{|l|}{$36 \mathrm{mo}$} & \multicolumn{3}{|l|}{$60 \mathrm{mo}$} \\
\hline & AUC(95\%Cl) & $\begin{array}{l}\text { z } \\
\text { statistic }\end{array}$ & $p^{\star}$ & AUC(95\%Cl) & $\begin{array}{l}\text { z } \\
\text { statistic }\end{array}$ & $p^{\star}$ & AUC(95\%Cl) & $\begin{array}{l}\text { Z } \\
\text { statistic }\end{array}$ & $p^{\star}$ & AUC(95\%Cl) & $\begin{array}{l}\text { z } \\
\text { statistic }\end{array}$ & $p^{\star}$ \\
\hline CEA & $\begin{array}{l}0.637(0.589- \\
0.682)\end{array}$ & 5.962 & $<0.001$ & $\begin{array}{l}0.586(0.537- \\
0.633)\end{array}$ & 1.768 & 0.077 & $\begin{array}{l}0.603(0.554- \\
0.649)\end{array}$ & 5.734 & $<0.001$ & $\begin{array}{l}0.636(0.589- \\
0.682)\end{array}$ & 6.270 & $<0.01$ \\
\hline CA19-9 & $\begin{array}{l}0.652(0.605- \\
0.697)\end{array}$ & 8.562 & $<0.001$ & $\begin{array}{l}0.598(0.550- \\
0.645)\end{array}$ & 2.138 & 0.033 & $\begin{array}{l}0.644(0.597- \\
0.690)\end{array}$ & 6.726 & $<0.001$ & $\begin{array}{l}0.655(0.608- \\
0.700)\end{array}$ & 8.841 & $<0.01$ \\
\hline NLR & $\begin{array}{l}0.754(0.710- \\
0.794)\end{array}$ & 4.039 & $<0.001$ & $\begin{array}{l}0.613(0.565- \\
0.660)\end{array}$ & 1.707 & 0.088 & $\begin{array}{l}0.713(0.668- \\
0.756)\end{array}$ & 3.676 & $<0.001$ & $\begin{array}{l}0.761(0.717- \\
0.801)\end{array}$ & 4.089 & $<0.01$ \\
\hline PLR & $\begin{array}{l}0.620(0.572- \\
0.666)\end{array}$ & 6.818 & $<0.001$ & $\begin{array}{l}0.581(0.533- \\
0.629)\end{array}$ & 1.651 & 0.099 & $\begin{array}{l}0.619(0.570- \\
0.665)\end{array}$ & 5.311 & $<0.001$ & $\begin{array}{l}0.613(0.565- \\
0.659)\end{array}$ & 7.419 & $<0.01$ \\
\hline LMR & $\begin{array}{l}0.680(0.634- \\
0.724)\end{array}$ & 4.711 & $<0.001$ & $\begin{array}{l}0.573(0.534- \\
0.621)\end{array}$ & 2.385 & 0.017 & $\begin{array}{l}0.653(0.605- \\
0.698)\end{array}$ & 4.406 & $<0.001$ & $\begin{array}{l}0.683(0.636- \\
0.727)\end{array}$ & 4.936 & $<0.01$ \\
\hline NCS & $\begin{array}{l}0.803(0.762- \\
0.840)\end{array}$ & - & - & $\begin{array}{l}0.654(0.607- \\
0.699)\end{array}$ & - & - & $\begin{array}{l}0.763(0.720- \\
0.803)\end{array}$ & - & - & $\begin{array}{l}0.811(0.770- \\
0.847)\end{array}$ & - & - \\
\hline
\end{tabular}

Note: (1) NLR: the neutrophil-to-lymphocyte ratio; PLR: the platelet-to-lymphocyte ratio; LMR: the lymphocyte-to-monocyte ratio. (2) NCS: the NLR-CA19-9 score. (3) * Comparison of AUC between the NLR-CA19-9 score and other variables.

\section{Figures}

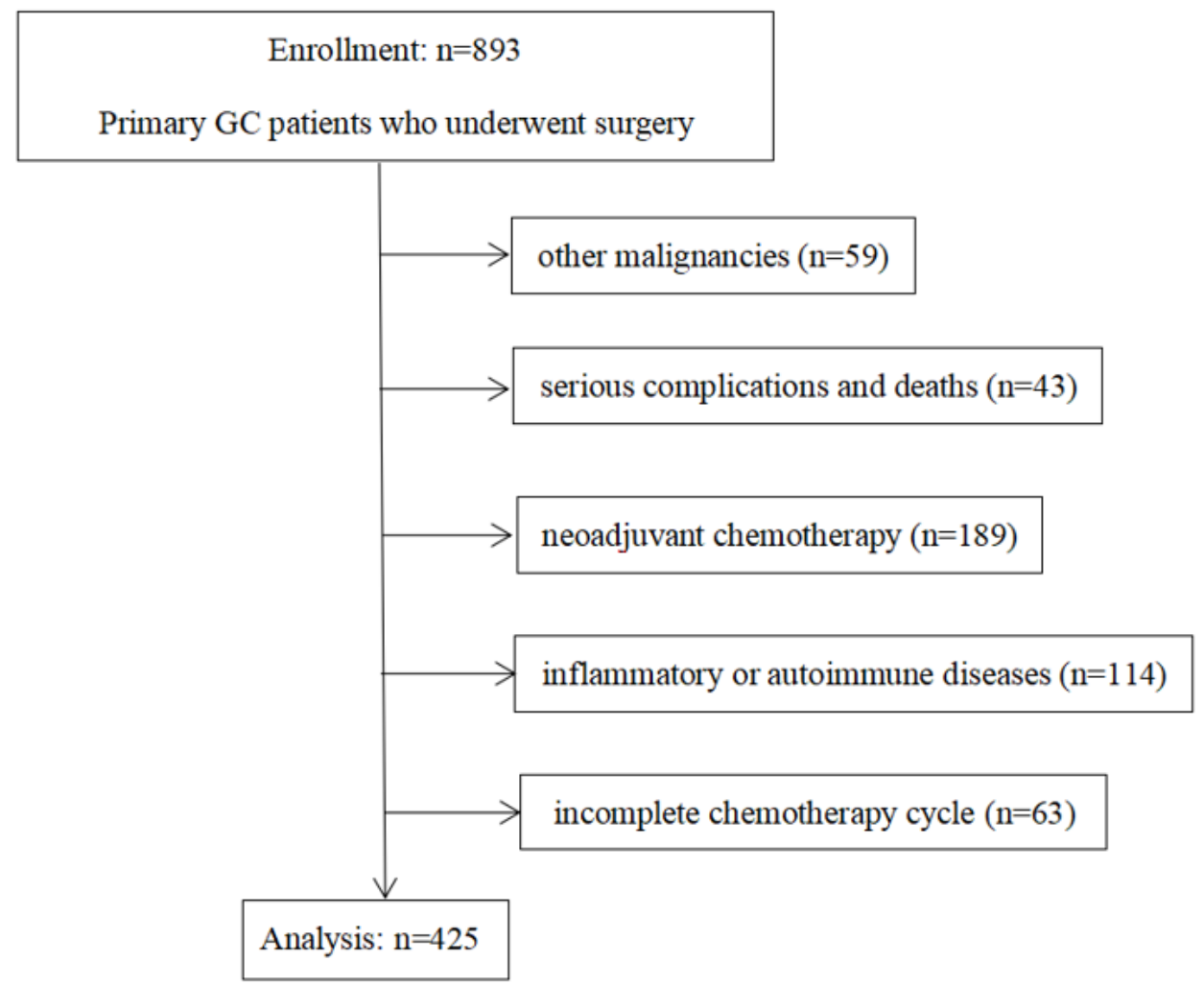

Figure 1

Consort flow diagram 
A total of 893 patients underwent gastrectomy for GC at the Second Hospital of Anhui Medical University between January 1, 2012 , and December 31, 2015. Finally, a total of 425 patients were selected for the study. GC: gastric cancer.

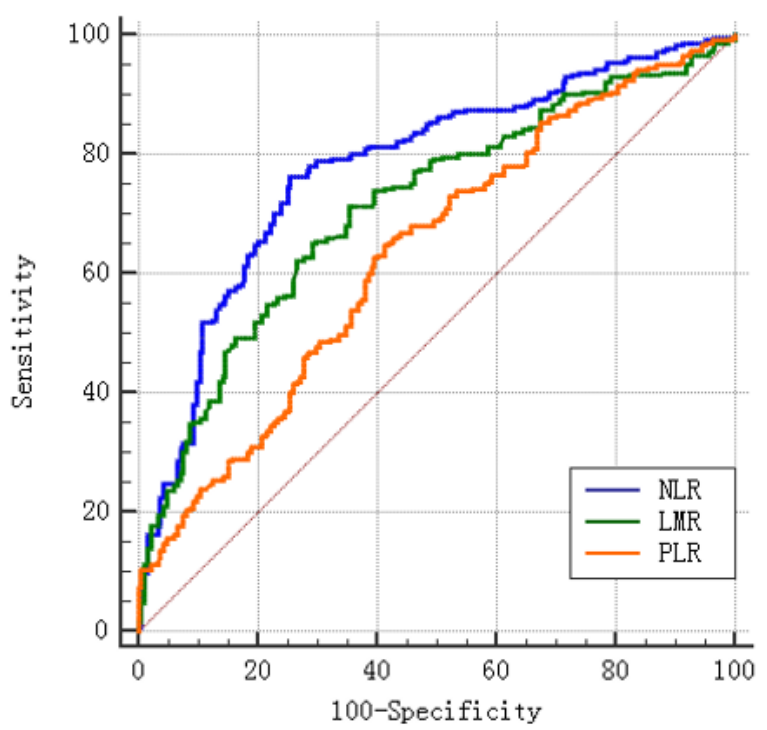

Figure 2

\section{ROC curves}

The optimal cutoff points of preoperative NLR, PLR and LMR for postoperative survivals were obtained by calculating the maximum Youden index of the ROC curves. NLR: the neutrophil-to-lymphocyte ratio; PLR: the platelet-to-lymphocyte ratio; LMR: the lymphocyte-to-monocyte ratio. 


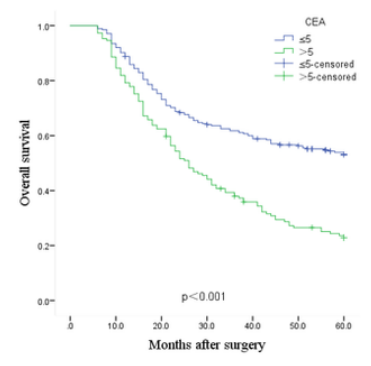

a

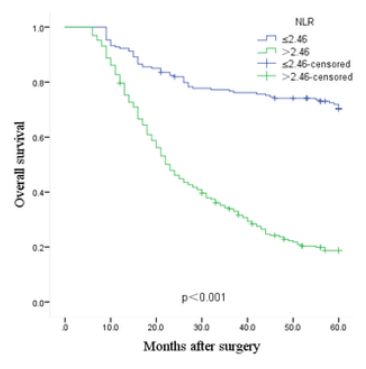

c

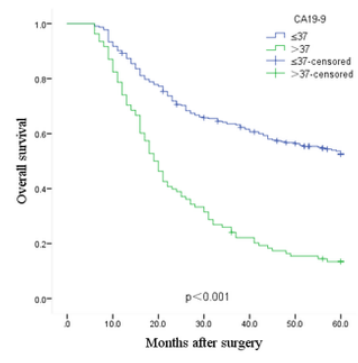

b

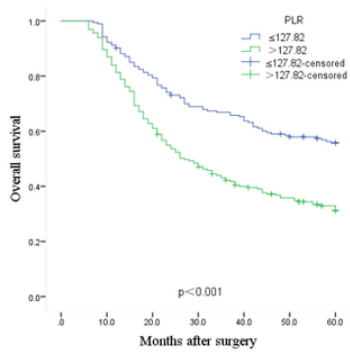

d

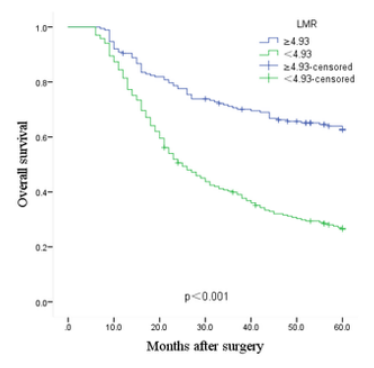

e

Figure 3

\section{Kaplan-Meier survival curves}

Kaplan-Meier estimates of the OS for patients according to CEA (a), CA19-9 (b), NLR (c), PLR (d) and LMR (e). NLR: the neutrophil-to-lymphocyte ratio; PLR: the platelet-to-lymphocyte ratio; LMR: the lymphocyte-to-monocyte ratio. OS: overall survival.

\section{Figure 4}

\section{Kaplan-Meier survival curve}

Kaplan-Meier estimates of the OS for patients according to NCS. NCS: the NLR-CA19-9 score. OS: overall survival. 


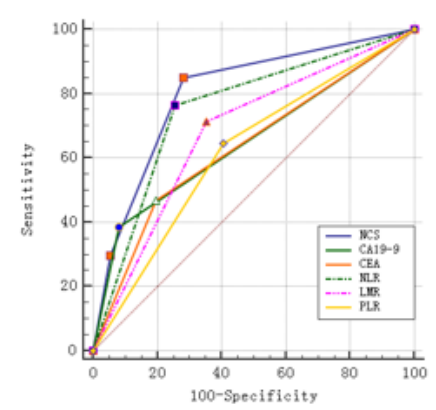

a

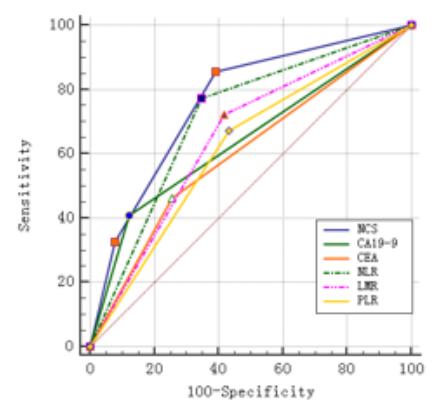

C

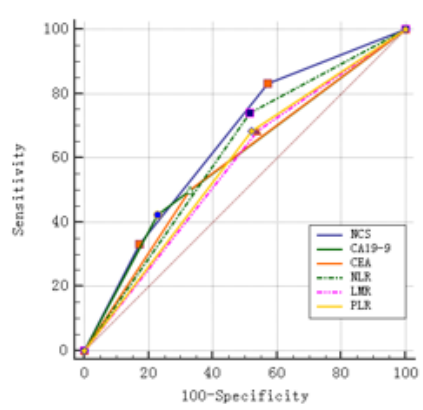

b

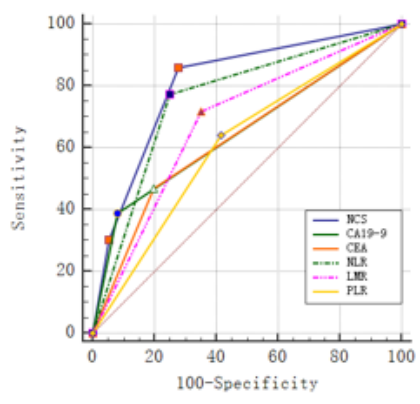

d

Figure 5

\section{The AUC of each index}

ROC analysis of NCS, CA19-9, CEA, NLR, PLR, LMR for OS, 1-, 3- and 5-year survival (a-d) after operation. NCS: the NLR-CA19-9 score. NLR: the neutrophil-tolymphocyte ratio; PLR: the platelet-to-lymphocyte ratio; LMR: the lymphocyte-to-monocyte ratio. OS: overall survival.

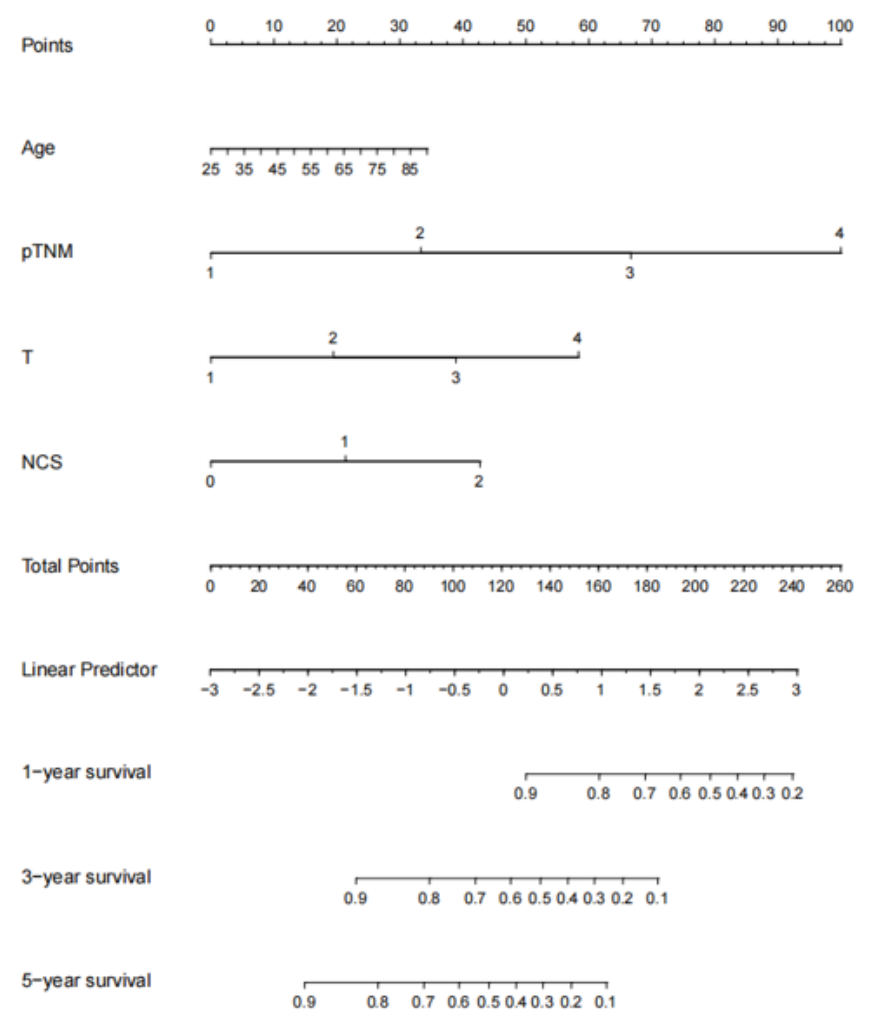

Figure 6

The nomogram 
Nomogram to predict 1-, 3- and 5-year OS for GC patients. NCS: the NLR-CA19-9 score. OS: overall survival.

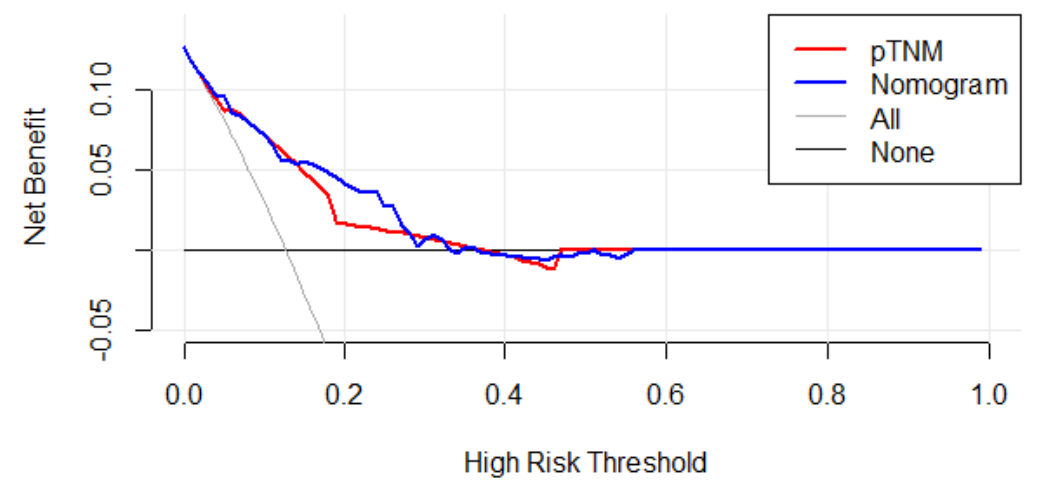

Figure 7

\section{The decision curve analysis}

The DCA of the nomogram and the AJCC TNM staging system to OS. AJCC, American Joint Committee on Cancer. OS: overall survival.

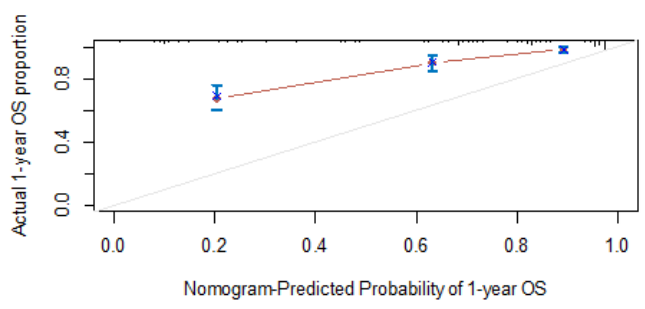

a

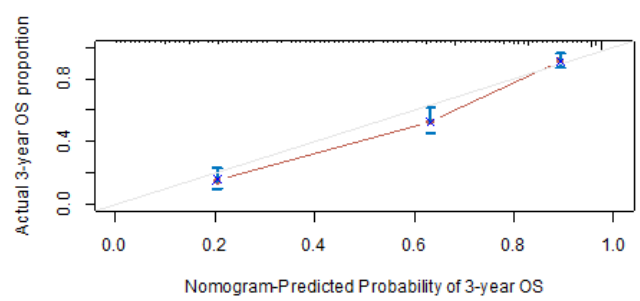

b

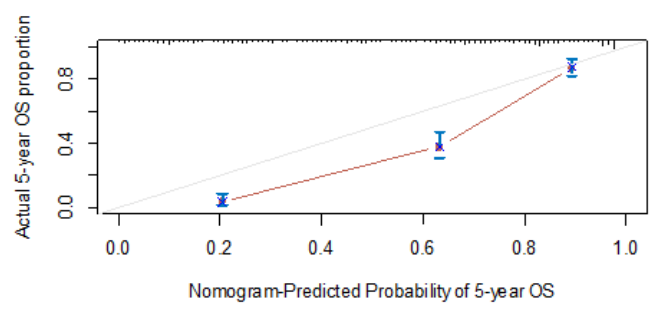

c

Figure 8

\section{The calibration curves}

The calibration curves to predict 1-, 3-, and 5-year OS (a-c). OS\overall survival. 